\title{
Preoperative pain neurophysiology education for lumbar radiculopathy: A randomized-controlled trial
}

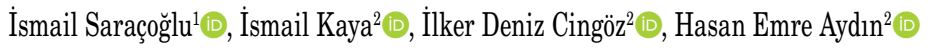 \\ ${ }^{1}$ Department of Physiotherapy and Rehabilitation, Faculty of Medicine, Kütahya Health Science University, Kütahya, Turkey \\ ${ }^{2}$ Department of Neurosurgery, Faculty of Medicine, Kütahya Health Science University, Kütahya, Turkey
}

Received: November 02, 2019 Accepted: May 06, 2020 Published online: September 01, 2021

\begin{abstract}
Objectives: This study aims to investigate the postoperative short-term effectiveness of preoperative pain neurophysiology education on pain severity, kinesiophobia, and disability in patients undergoing lumbar surgery for radiculopathy.

Patients and methods: Between April 2019 and August 2019, a total of 41 patients (22 males, 19 females; mean age $52.1 \pm 9.5$ years; range, 37 to 64 years) scheduled for lumbar radiculopathy surgery were randomized to receive either preoperative routine education only (control group, $\mathrm{n}=20$ ) or a 70 - min pain neurophysiology education in addition to preoperative routine education (intervention group, $\mathrm{n}=21$ ). The patients were evaluated for the following outcomes prior to surgery (baseline) and at 12 weeks after surgery: low back pain and leg pain using Numeric Pain Rating Scale, disability using Oswestry Disability Index), and kinesiophobia using Tampa Scale for Kinesiophobia.

Results: There were no statistically significant differences in low back pain ( $\mathrm{p}=0.121)$, leg pain $(\mathrm{p}=0.142$ ), and the length of stay hospital $(p=0.110)$ between the groups. However, the interaction effects of intervention group were superior to control group regarding disability $(\mathrm{p}=0.042)$ and kinesiophobia $(\mathrm{p}<0.001)$.

Conclusion: The addition of pain neurophysiology education to routine education following lumbar radiculopathy surgery yields significant improvements for disability and kinesiophobia, although no additional benefits is seen regarding the pain severity and length of stay in hospital in the short-term.
\end{abstract}

Keywords: Chronic pain, low back pain, neurosurgery, pain neurophysiology education, patient education, radiculopathy.

Conservative treatment of lumbar radiculopathy (LR) is reported to possibly fail and exacerbates symptoms; therefore, lumbar surgery is usually planned after failed conservative treatment. ${ }^{[1,2]}$ The primary surgical intervention for LR is lumbar laminectomy or laminotomy with or without discectomy. ${ }^{[3]}$ The success rate of these surgical interventions has been reported as 60 to $90 \% \cdot{ }^{[4-7]}$ Although this rate may be considered successful, 10 to $40 \%$ of patients may experience pain, movement loss, and function losses postoperatively. ${ }^{[3]}$

A rehabilitation program consisting of exercise and physical therapy is recommended to patients due to persistent pain and disability after surgery. ${ }^{[8,9]}$ However, few patients receive postoperative rehabilitation, as surgeons rarely refer them to rehabilitation programs and/or due to their personal preferences. ${ }^{[10,11]}$ In addition, studies on this subject have reported that the long-term effectiveness of postoperative rehabilitation is low. ${ }^{[11,12]}$

One of the strategies designed to reduce postoperative complications and disability is preoperative patient education. ${ }^{[13]}$ Anatomical and biomechanical explanations are usually used in preoperative education, aiming at increasing patients' knowledge level and reducing their surgical anxiety, postoperative pain, and length of hospital stay.

Corresponding author: İlker Deniz Cingöz, PhD. Kütahya Sağlık Bilimleri Üniversitesi Tip Fakültesi Beyin ve Sinir Cerrrahisi Anabilim Dalı, 43100 Kütahya, Türkiye. e-mail: i.d.cingoz@hotmail.com 
However, systematic reviews conducted to examine the effectiveness of these education methods revealed that they had no additional effects on patients undergoing surgery. ${ }^{[14]}$

Pain Neurophysiology Education (PNE) is frequently used in chronic pain patients and has been shown to be effective in chronic pain disorders and recently been applied in preoperative patient education, as well. ${ }^{[15,16]}$ Instead of anatomical and biomedical explanations, PNE includes explanations of the biological and neurophysiological processes related to the painful situations in which patients find themselves. ${ }^{[15]}$ To date, few studies. ${ }^{[17-19]}$ have been conducted on the effectiveness of preoperative education in patients undergoing lumbar surgery and current reports suggest that PNE may be effective in reducing pain and improving physical function. Besides, the addition of a single PNE session prior to surgery for LR results in significant healthcare savings over three years. ${ }^{[18]}$ However, previous studies are unable to explore the effectiveness a PNE session on the length of stay after surgery. Besides, there is no PNE study in patients undergoing lumbar surgery in Turkey.

In the present study, we aimed to investigate the postoperative short-term effectiveness of preoperative PNE on pain severity, disability, kinesiophobia, and the length of stay in patients undergoing surgery for LR.

\section{PATIENTS AND METHODS}

This study was designed as a single-blind, prospective, randomized-controlled study. The study was conducted at Neurosurgery Department of Faculty of Medicine, Kütahya Health Science University between April 2019 and August 2019. A written informed consent was obtained from each patient. The study protocol was approved by the Faculty of Medicine, Kütahya Health Science University Clinical Research Ethics Committee (No. 2019-19/3). The study was conducted in accordance with the principles of the Declaration of Helsinki.

Lumbar radiculopathy surgery was decided by the surgeons for patients who were admitted to neurosurgery department with low back pain. Surgery was planned at the discretion of the surgeons, and the operation date was planned by the assistants and administrative and procedural information was provided to each patient. Meanwhile, all patients were informed and invited to participate in this study exploring the effects of two preoperative education programs.

Patients diagnosed with LR who were scheduled for surgery were included in this study. Inclusion criteria were as follows: age $>18$ years or $<65$ years; being scheduled for LR surgery; and willingness to participate in the study and comply with the prespecified follow-up visits. Exclusion criteria were as follows: being scheduled for surgery other than LR; being scheduled for instrumental lumbar surgery (spinal fusion, arthroplasty, etc.); illiteracy in Turkish language; and presence of chronic pain-related conditions (fibromyalgia, chronic fatigue syndrome, etc.).

A total of 63 patients were screened for eligibility and, after exclusions, 44 agreed to participate and were enrolled in the study. Of the initial group of 44 patients (22 assigned to the intervention group, 22 assigned to the control group), three participants were excluded from the study, as they did not comply with their follow-ups, and the study was completed with 41 patients (22 males, 19 females; mean age $52.1 \pm 9.5$ years; range, 37 to 64 years) at the end of 12 weeks of follow-up. The study flow chart is shown in Figure 1.

Concealed randomization was performed using computer-generated numbers. All patients were given an envelope, which randomly assigned them to either routine education (control group, $\mathrm{n}=20$ ) or PNE in addition to routine education (intervention group, $\mathrm{n}=21$ ). The envelopes contained identical information except that patients in the intervention group were asked to schedule a 70-min PNE session with physician to deliver preoperative PNE session. The patients in the intervention group were told that this was the usual practice of surgeons. The surgeons and their assistants were blinded to the group allocation.

\section{Interventions}

The patients in the control group $(n=20)$ received standard preoperative education from their surgeons. This standard education covers information about lumbar anatomy, surgical procedure, risks associated with surgery, general hospital procedures, and length of hospital stay, daily life activities, and physical activity after surgery.

The patients in the intervention group $(n=21)$ received a 70-min PNE session in addition to standard preoperative education. The development and content of PNE has been published elsewhere. ${ }^{[18,19]}$ In PNE, the patient is educated about the neurophysiology 


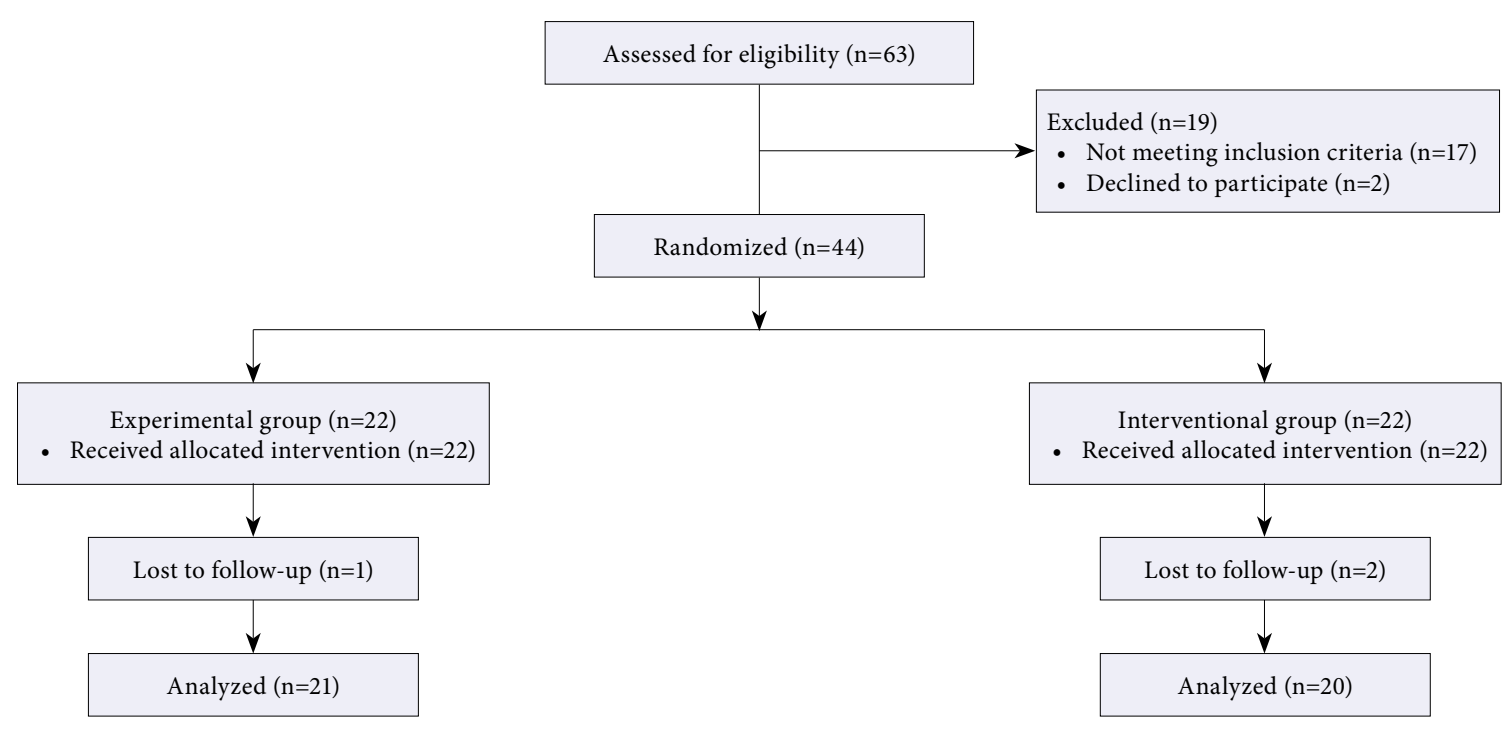

Figure 1. CONSORT flow diagram.

of pain, central sensitization, surgical experiences and environmental issues effects on nerve sensitivity, calming the nervous system, recover after surgery and the role of aerobic exercise to improve disability and pain. ${ }^{[15,18,19]}$ The PNE sessions were conducted by an experienced physician certified in PNE in face-to-face, one-on-one sessions lasting $70 \mathrm{~min}$. Metaphors, anecdotes, and pictures were used in PNE sessions.

\section{Outcomes}

\section{Pain severity}

Numeric Pain Rating Scale (NPRS) was used to assess the participants' pain levels. Clinimetric characteristics of the NPRS are adequately established ${ }^{[20]}$ and the test-retest reliability of the scale was found to be high $(r=0.82)$ in patients with chronic pain. ${ }^{[21]}$ In the NPRS, patients are asked to verbally rate the severity of their pain on a scale from 0 to 10 .

\section{Disability}

The participants' level of disability was evaluated using the Turkish adaptation of the Oswestry Disability Index (ODI), which was developed by Fairbank et al. ${ }^{[22]}$ The scale comprises 10 items, each with six options worth 0 to 5 points. For each item, participants are asked to mark the option that best describes their current condition. A high total score indicates severe disability. ${ }^{[23]}$ Intertester reliability of the ODI was very high (intraclass correlation coefficient $=0.938$ ) and test-retest reliability was also high (intraclass correlation coefficient $=0.918) .{ }^{[23]}$

\section{Kinesiophobia}

The Tampa Scale for Kinesiophobia (TSK) was used for the assessment of kinesiophobia. The TSK is a 17-item questionnaire developed to measure the fear of movement/re-injury. The scale includes injury/re-injury and fear-avoidance parameters in work-related activities. The items are rated on a 4-point Likert-type scale ( $1=$ definitely disagree, $4=$ completely agree) and the total score is between 17 and 68 points. Higher total score indicates higher level of kinesiophobia. ${ }^{[24]}$ Test-retest reliability of the Turkish version of the TSK was found to be excellent (intraclass correlation coefficient $=0.867){ }^{[24]}$

\section{Statistical analysis}

The sample size calculation was performed using the $G^{\star}$ Power version 3.1.9.2 software (Heinrich-HeineUniversität Düsseldorf, Düsseldorf, Germany), based on a moderate effect size (0.25) for low back pain intensity values in the study of Louw et al. ${ }^{[19]}$ Given the three measurements in the two groups, correction of sphericity was determined as 0.5 . For statistical power of 0.80 and an alpha ( $\alpha$ ) level of 0.05 , a sample size of 38 patients (19 participants in each group) was required. The enrolment goal was set at 44 participants to account for possible dropout (15\%).

Statistical analysis was performed using the IBM SPSS version 20.0 software (IBM Corp., Armonk, NY, USA). Continuous variables were expressed in mean \pm standard deviation (SD) or median (min-max), while categorical variables were expressed in number 
and frequency. All variables were assessed for normal distribution using the Kolmogorov-Smirnov or Shapiro-Wilk test. The continuous data of the intervention and control groups were compared using independent samples t-test. The chi-square test was used to compare the categorical data of two groups. Internal consistency of the ODI and TSK for the first assessment was evaluated using the Cronbach's $\alpha$. The Cronbach's a values of more than 0.75 indicate good reliability, while those less than 0.75 indicate poor-to-moderate reliability. ${ }^{[25]}$

The length of stay in hospital was compared between the groups by using the t-test. To detect differences between the groups, 2 (group: intervention and control) $\times 2$ (time: baseline and $12^{\text {th }}$ week) analysis of variances on different outcome measures (leg pain, back pain, ODI and TKS) was conducted. If interactions between the group and time were observed, the main effects using a Bonferroni correction were used. A $p$ value of $<0.05$ was considered statistically significant. If no interaction was observed, then the main effects were analyzed. Partial eta-squared $(\eta 2)$ calculated by the SPSS was used to gauge the effect size. The $\eta 2$ values less than 0.01 indicate a small effect size, 0.06 indicates a medium effect size, and values over 0.14 indicate a large effect size. ${ }^{[26]}$

\section{RESULTS}

A total of 41 patients underwent lumbar surgery. The mean age was $52.7 \pm 9.6$ years in the intervention group and $51.4 \pm 9.2$ years in the control group. No significant differences were observed between the groups in terms of age ( $\mathrm{p}=0.661)$, height $(\mathrm{p}=0.802)$, body weight $(\mathrm{p}=0.428)$, body mass index $(\mathrm{p}=0.522)$, duration of pain $(\mathrm{p}=0.571)$, sex $(\mathrm{p}=0.867)$, and education status $(p=0.992)$. Demographic characteristics of the patients are shown in Table 1. In addition, both groups had similar baseline scores for pain intensity, disability, and kinesiophobia (Table 2).

Although the main effects for time were statistically significant for NPRS leg pain $(\mathrm{p}<0.001)$ and low back pain $(p<0.001)$, there were no significant interactions for NPRS leg pain $(\mathrm{p}=0.142)$ and low back pain $(\mathrm{p}=0.121)$. The ODI for both groups showed good internal consistency with a Cronbach's a value of 0.802 . Examination of differences in the mean ODI scores between the treatment and control groups showed that group $(\mathrm{p}=0.001)$, time $(\mathrm{p}<0.001)$, and interaction effects $(p=0.042)$ were statistically significant. The intervention group showed statistically higher improvements than the control group for disability (inter-group difference $=3.75 \pm 1.78$; $95 \%$ CI: 0.10 to 7.36 ; $\mathrm{p}=0.042)$. A large effect size was found $(\eta 2=0.407)$. Similarly, The TSK for both groups showed good internal consistency with Cronbach's a value of 0.768. Besides, the analysis of differences in the mean TSK scores revealed statistically significant group $(\mathrm{p}<0.001)$, time $(\mathrm{p}<0.001)$, and interaction effects $(\mathrm{p}<0.001)$. The intervention group showed statistically higher improvements than the control group in terms of kinesiophobia (inter-group difference $=5.6 \pm 1.1$; $95 \%$ CI: 3.37 to $7.89 ; \mathrm{p}<0.001$ ) (Table 3). A large effect size was detected $(\eta 2=0.376)$. Additionally, there

\begin{tabular}{|c|c|c|c|c|c|c|c|}
\hline \multicolumn{8}{|c|}{$\begin{array}{c}\text { TABLE } 1 \\
\text { Demographic characteristics of patients }\end{array}$} \\
\hline & \multicolumn{3}{|c|}{ Experimental group $(n=21)$} & \multicolumn{3}{|c|}{ Interventional group $(n=20)$} & \multirow[b]{2}{*}{$p$} \\
\hline & $\mathrm{n}$ & $\%$ & Mean \pm SD & $\mathrm{n}$ & $\%$ & Mean \pm SD & \\
\hline Age (year) & & & $52.7 \pm 9.6$ & & & $51.4 \pm 9.2$ & $0.661^{\star}$ \\
\hline Height $(\mathrm{cm})$ & & & $169.2 \pm 11.4$ & & & $168.4 \pm 8.6$ & $0.802^{*}$ \\
\hline Weight $(\mathrm{kg})$ & & & $78.6 \pm 11.2$ & & & $75.8 \pm 11.6$ & $0.428^{*}$ \\
\hline $\operatorname{BMI}\left(\mathrm{kg} / \mathrm{m}^{2}\right)$ & & & $27.5 \pm 5.3$ & & & $26.6 \pm 2.6$ & $0.522^{\star}$ \\
\hline Duration of pain (month) & & & $37.5 \pm 16.6$ & & & $34.6 \pm 15.4$ & $0.571^{\star}$ \\
\hline Sex & & & & & & & $0.867 \dagger$ \\
\hline Female & 10 & 47.6 & & 9 & 45.0 & & \\
\hline Male & 11 & 52.4 & & 11 & 55.0 & & \\
\hline Education & & & & & & & $0.992 \dagger$ \\
\hline Primary school & 13 & 61.9 & & 12 & 60 & & \\
\hline High school & 6 & 28.6 & & 6 & 30 & & \\
\hline University & 2 & 9.5 & & 2 & 10 & & \\
\hline
\end{tabular}




\begin{tabular}{|c|c|c|c|}
\hline \multicolumn{4}{|c|}{$\begin{array}{c}\text { TABLE } 2 \\
\text { Outcome measures at baseline }\end{array}$} \\
\hline & Experimental group $(n=21)$ & Interventional group $(n=20)$ & \\
\hline & Mean \pm SD & Mean \pm SD & $p$ \\
\hline Leg pain (NPRS 0-10) & $7.2 \pm 1.4$ & $7.4 \pm 1.5$ & 0.605 \\
\hline Back pain (NPRS 0-10) & $7.9 \pm 1.8$ & $8.2 \pm 1.3$ & 0.471 \\
\hline ODI $(0-100)$ & $43.5 \pm 8.2$ & $43.0 \pm 4.0$ & 0.806 \\
\hline TKS (17-68) & $41.5 \pm 3.9$ & $42.8 \pm 3.0$ & 0.238 \\
\hline
\end{tabular}

\begin{tabular}{|c|c|c|c|c|c|c|c|c|}
\hline \multicolumn{9}{|c|}{$\begin{array}{c}\text { TABLE } 3 \\
\text { Changes over time within and between groups }\end{array}$} \\
\hline & \multirow{2}{*}{$\begin{array}{c}\text { Baseline } \\
\text { Mean } \pm \text { SD }\end{array}$} & \multirow{2}{*}{$\frac{\text { At } 12^{\text {th }} \text { weeks }}{\text { Mean } \pm \text { SD }}$} & \multicolumn{2}{|c|}{ Group effect } & \multicolumn{2}{|c|}{ Time effect } & \multicolumn{2}{|c|}{ Interaction effect } \\
\hline & & & $\mathrm{F}$ & $p$ & $\mathrm{~F}$ & $p$ & $\mathrm{~F}$ & $p$ \\
\hline Leg pain (NPRS 0-10) & & & 1.37 & 0.216 & 145.93 & $0.001^{*}$ & 2.15 & 0.142 \\
\hline Experimental group & $5.2 \pm 1.4$ & $2.1 \pm 1.6$ & & & & & & \\
\hline Interventional group & $5.4 \pm 1.5$ & $2.3 \pm 1.8$ & & & & & & \\
\hline Back pain (NPRS 0-10) & & & 0.97 & 0.376 & 276.87 & $0.001^{*}$ & 2.44 & 0.121 \\
\hline Experimental group & $7.9 \pm 1.8$ & $1.6 \pm 1.7$ & & & & & & \\
\hline Interventional group & $8.2 \pm 1.3$ & $2.6 \pm 2.1$ & & & & & & \\
\hline ODI $(0-100)$ & & & 26.11 & $0.001^{*}$ & 234.84 & $0.001^{*}$ & 4.42 & $0.042^{*}$ \\
\hline Experimental group & $43.5 \pm 8.2$ & $21.3 \pm 6.6$ & & & & & & \\
\hline Interventional group & $43.0 \pm 4.0$ & $31.5 \pm 5.8$ & & & & & & \\
\hline TKS (17-68) & & & 22.88 & $0.001^{*}$ & 90.30 & $0.001^{*}$ & 25.43 & $0.001^{*}$ \\
\hline Experimental group & $41.5 \pm 3.4$ & $31.2 \pm 5.1$ & & & & & & \\
\hline Interventional group & $42.8 \pm 3.0$ & $37.5 \pm 3.9$ & & & & & & \\
\hline
\end{tabular}

were no significant differences between two groups according to the length of stay in hospital (inter-group difference $=0.25 ; 95 \%$ CI: 0.05 to $0.55 ; \mathrm{p}=0.110$ ).

\section{DISCUSSION}

The present study showed that the addition of a 70-min preoperative pain-specific neuroscience education program to routine education had statistically and clinically superior outcomes for disability and kinesiophobia for patients undergoing LR surgery at 12 weeks of follow-up. Although leg and back pain improved at any time point, there was no statistically significant difference between the intervention and control groups. Besides, there was no significant difference in the length of stay in hospital between the groups.

In our study, we found that majority of patients were at the middle-age with low education status. We also determined limited lumbar mobility in the majority of patients. We found that severity of low back pain was high and functional status severely limited their daily lives. There was no significant difference in terms of sex in our study, although Skaf et al. ${ }^{[27]}$ reported that postoperative pain was more common in women. Similar to previous studies, ${ }^{[7,28,29]}$ we found a notable postoperative pain ratings following lumbar surgery.

In addition to non-steroidal anti-inflammatory drugs, muscle relaxants, antidepressants, and antiepileptics, perioperative rehabilitation programs are also frequently used for the prevention of postoperative pain. ${ }^{[30,31]}$ Perioperative rehabilitation is usually enhanced with some type of education as a conceivable strategy to improve surgical success ${ }^{[13]}$ and a survey study reported that many surgeons provided some of education form of education to their patients before they underwent surgery for LR. ${ }^{[32]}$ The education mainly covers anatomical and biomedical 
topics in the previous preoperative education studies and such educational form seems to be ineffective, when patients are still experiencing pain and disability. ${ }^{[14,33]}$ Besides, Louw et al. ${ }^{[34]}$ reported that patients undergoing surgery desired to improve knowledge about their pain and the impact of surgery in addition to information about the pathology, surgical procedure, and associated risks. Therefore, the education form in the current study, namely PNE, mainly focused on the pain neurophysiology and influence of cognitive-behavioral factors on their recovery following LR surgery.

Several studies have demonstrated that PNE is effective method for pain relief, improving functions, changing pain beliefs and attitudes, decreasing kinesiophobia, and reducing healthcare expenditure in patients with several chronic pain disorders. ${ }^{[35-37]}$ It has been advocated that the action mechanism for PNE is related to function of brain-orchestrated nociceptive inhibition. ${ }^{[38]}$ By understanding of pain well, the threat of pain would decrease, leading to more effective pain coping strategies. ${ }^{[39]}$ The dysfunction of nociceptive inhibition is also one of the cardinal features of postoperative consistent pain. ${ }^{[40]}$ It also explains why patients are still in pain after tissue healing process following surgery. At this stage, PNE can help to restore brain-orchestrated nociceptive inhibition and reduce postoperative pain and dysfunction. ${ }^{[15]}$

Our results demonstrated that the addition of a 70-min PNE session to routine education resulted in superior outcomes in postoperative disability and kinesiophobia for patients undergoing LR, although there was no significant result regarding the length of stay in hospital and pain severity. In the literature, there are insufficient robust studies to explore the effectiveness preoperative PNE following lumbar surgery. Similar to our results, a case series study showed that the short-term effects of preoperative PNE were promising regarding back performance, pain catastrophizing, and beliefs about pain following lumbar surgery. ${ }^{[15]}$ However, a recent multi-center, randomized-controlled study demonstrated that the addition of a 30-min PNE session to routine education was not superior to routine education alone regarding pain severity and disability for patients undergoing LR surgery. ${ }^{[19]}$ Although they found that PNE group was superior to routine education group at one-month follow-up, the difference was not significant at any time point. The differences in findings can be explained by timing of education. Louw et al. ${ }^{[19]}$ provided a $30-\mathrm{min}$ verbal education form prior to surgery, whereas our study provided the education in a 70 -min verbal form. We believe that 30 -min session is not enough to re-conceptualize of pain. Moreover, Louw et al. ${ }^{[19]}$ conducted a multi-center study and the differences between the practitioners and methods they used may have influenced the outcomes.

The present study has certain limitations. First, the results cover only 12-week follow-up. Future studies should examine the long-term effectiveness such as one-year or two-year follow up periods. Second, we were unable to examine the difference between two groups regarding healthcare expenditure, as we did not follow patients in the long-term. Future studies should investigate the long-term effectiveness and clarify any potential economic advantage of the addition of PNE to routine education for patients undergoing lumbar surgery in Turkey. Third, we were unable to evaluate whether the participants understood well the information about pain. It would have been reasonable to assess whether PNE increased pain knowledge using a questionnaire such as Neurophysiology of Pain Questionnaire.

In conclusion, the addition of PNE to routine education following LR surgery improved disability and kinesiophobia, although there were no additional benefits regarding pain severity and length of stay in hospital in the short-term. Future studies should investigate the long-term effects and cost-efficacy of this educational method following LR surgery.

Declaration of conflicting interests

The authors declared no conflicts of interest with respect to the authorship and/or publication of this article.

Funding

The authors received no financial support for the research and/or authorship of this article.

\section{REFERENCES}

1. Jacobs WC, van Tulder M, Arts M, Rubinstein SM, van Middelkoop M, Ostelo R, et al. Surgery versus conservative management of sciatica due to a lumbar herniated disc: a systematic review. Eur Spine J 2011;20:513-22.

2. Manchikanti L, Singh V, Falco FJ, Cash KA, Pampati V. Evaluation of lumbar facet joint nerve blocks in managing chronic low back pain: a randomized, double-blind, controlled trial with a 2-year follow-up. Int J Med Sci 2010;7:124-35.

3. Ostelo RW, de Vet HC, Waddell G, Kerckhoffs MR, Leffers $\mathrm{P}$, van Tulder M. Rehabilitation following first-time lumbar disc surgery: a systematic review within the framework of the cochrane collaboration. Spine (Phila $\mathrm{Pa}$ 1976) 2003;28:209-18. 
4. Findlay GF, Hall BI, Musa BS, Oliveira MD, Fear SC. A 10-year follow-up of the outcome of lumbar microdiscectomy. Spine (Phila Pa 1976) 1998;23:1168-71.

5. Keskimäki I, Seitsalo S, Osterman H, Rissanen P. Reoperations after lumbar disc surgery: a population-based study of regional and interspecialty variations. Spine (Phila Pa 1976) 2000;25:1500-8.

6. Loupasis GA, Stamos K, Katonis PG, Sapkas G, Korres DS, Hartofilakidis G. Seven- to 20-year outcome of lumbar discectomy. Spine (Phila Pa 1976) 1999;24:2313-7.

7. Yorimitsu E, Chiba K, Toyama Y, Hirabayashi K. Longterm outcomes of standard discectomy for lumbar disc herniation: a follow-up study of more than 10 years. Spine (Phila Pa 1976) 2001;26:652-7.

8. Danielsen JM, Johnsen R, Kibsgaard SK, Hellevik E. Early aggressive exercise for postoperative rehabilitation after discectomy. Spine (Phila Pa 1976) 2000;25:1015-20.

9. Dolan P, Greenfield K, Nelson RJ, Nelson IW. Can exercise therapy improve the outcome of microdiscectomy? Spine (Phila Pa 1976) 2000;25:1523-32.

10. McGregor AH, Dicken B, Jamrozik K. National audit of post-operative management in spinal surgery. BMC Musculoskelet Disord 2006;7:47.

11. Ostelo RW, Costa LO, Maher CG, de Vet HC, van Tulder MW. Rehabilitation after lumbar disc surgery: an update Cochrane review. Spine (Phila $\mathrm{Pa}$ 1976) 2009;34:1839-48.

12. Beaupre LA, Lier D, Davies DM, Johnston DB. The effect of a preoperative exercise and education program on functional recovery, health related quality of life, and health service utilization following primary total knee arthroplasty. J Rheumatol 2004;31:1166-73.

13. Oshodi TO. The impact of preoperative education on postoperative pain. Part 2. Br J Nurs 2007;16:790-7.

14. Johansson K, Nuutila L, Virtanen H, Katajisto J, Salanterä S. Preoperative education for orthopaedic patients: systematic review. J Adv Nurs 2005;50:212-23.

15. Goudman L, Huysmans E, Ickmans K, Nijs J, Moens M, Putman K, et al. A Modern Pain Neuroscience Approach in Patients Undergoing Surgery for Lumbar Radiculopathy: A Clinical Perspective. Phys Ther 2019;99:933-45.

16. Wijma AJ, van Wilgen CP, Meeus M, Nijs J. Clinical biopsychosocial physiotherapy assessment of patients with chronic pain: The first step in pain neuroscience education. Physiother Theory Pract 2016;32:5:368-84.

17. Louw A, Diener I, Puentedura EJ. The short term effects of preoperative neuroscience education for lumbar radiculopathy: A case series. Int J Spine Surg 2015;9:11.

18. Louw A, Diener I, Landers MR, Zimney K, Puentedura EJ. Three-year follow-up of a randomized controlled trial comparing preoperative neuroscience education for patients undergoing surgery for lumbar radiculopathy. J Spine Surg 2016;2:289-98.

19. Louw A, Diener I, Landers MR, Puentedura EJ. Preoperative pain neuroscience education for lumbar radiculopathy: a multicenter randomized controlled trial with 1-year follow-up. Spine (Phila Pa 1976) 2014;39:1449-57.
20. Childs JD, Piva SR, Fritz JM. Responsiveness of the numeric pain rating scale in patients with low back pain. Spine (Phila Pa 1976) 2005;30:1331-4.

21. Jensen MP, Turner JA, Romano JM, Fisher LD. Comparative reliability and validity of chronic pain intensity measures. Pain 1999;83:157-62.

22. Fairbank JC, Couper J, Davies JB, O'Brien JP. The Oswestry low back pain disability questionnaire. Physiotherapy 1980;66:271-3.

23. Yakut E, Düger T, Oksüz C, Yörükan S, Ureten K, Turan $\mathrm{D}$, et al. Validation of the Turkish version of the Oswestry Disability Index for patients with low back pain. Spine (Phila Pa 1976) 2004;29:581-5.

24. Tunca Yılmaz Ö, Yakut Y, Uygur F, Uluğ N. Tampa Kinezyofobi Ölçeği'nin Türkçe versiyonu ve test-tekrar test güvenirliği. Fizyoter Rehabil 2011;22:44-9.

25. Portney L, Watkins M. Reliability of measurements. Foundations of clinical research: applications to practice. 3rd ed. New Jersey: Pearson Education Inc; 2009.

26. Cohen J. Statistical power analysis for the behavioral sciences. 2nd ed. New York: Routledge; 2013.

27. Skaf G, Bouclaous C, Alaraj A, Chamoun R. Clinical outcome of surgical treatment of failed back surgery syndrome. Surg Neurol 2005;64:483-8.

28. Nijs J, Meeus M, Cagnie B, Roussel NA, Dolphens M, Van Oosterwijck J, et al. A modern neuroscience approach to chronic spinal pain: combining pain neuroscience education with cognition-targeted motor control training. Phys Ther 2014;94:730-8.

29. Moseley GL, Nicholas MK, Hodges PW. A randomized controlled trial of intensive neurophysiology education in chronic low back pain. Clin J Pain 2004;20:324-30.

30. Ruan X, Tadia R, Couch JP, Ruan J, Chiravuri S. Severe peripheral edema during an outpatient continuous epidural morphine infusion trial in a patient with failed back surgery syndrome. Pain Physician 2008;11:363-7.

31. Louw A, Diener I, Butler DS, Puentedura EJ. Preoperative education addressing postoperative pain in total joint arthroplasty: review of content and educational delivery methods. Physiother Theory Pract 2013;29:175-94.

32. McDonald S, Page MJ, Beringer K, Wasiak J, Sprowson A. Preoperative education for hip or knee replacement. Cochrane Database Syst Rev 2014;2014:CD003526.

33. Kastanias P, Denny K, Robinson S, Sabo K, Snaith K. What do adult surgical patients really want to know about pain and pain management? Pain Manag Nurs 2009;10:22-31.

34. van Ittersum $M W$, van Wilgen $C P$, van der Schans CP, Lambrecht L, Groothoff JW, Nijs J. Written pain neuroscience education in fibromyalgia: a multicenter randomized controlled trial. Pain Pract 2014;14:689-700.

35. Van Oosterwijck J, Nijs J, Meeus M, Truijen S, Craps J, Van den Keybus N, et al. Pain neurophysiology education improves cognitions, pain thresholds, and movement performance in people with chronic whiplash: a pilot study. J Rehabil Res Dev 2011;48:43-58.

36. Van Oosterwijck J, Meeus M, Paul L, De Schryver M, Pascal A, Lambrecht L, et al. Pain physiology education improves health status and endogenous pain inhibition in fibromyalgia: a double-blind randomized controlled trial. Clin J Pain 2013;29:873-82. 
37. Ghroubi S, Elleuch H, Baklouti S, Elleuch MH. Chronic low back pain and vertebral manipulation. Ann Readapt Med Phys 2007;50:570-6.

38. Moseley GL. A pain neuromatrix approach to patients with chronic pain. Man Ther 2003;8:130-40.

39. Fernández-Lao C, Cantarero-Villanueva I, Fernándezde-las-Peñas C, Del-Moral-Ávila R, Menjón-Beltrán S, Arroyo-Morales M. Widespread mechanical pain hypersensitivity as a sign of central sensitization after breast cancer surgery: comparison between mastectomy and lumpectomy. Pain Med 2011;12:72-8.

40. Louw A, Diener I, Butler DS, Puentedura EJ. The effect of neuroscience education on pain, disability, anxiety, and stress in chronic musculoskeletal pain. Arch Phys Med Rehabil 2011;92:2041-56. 